\title{
SCOTT MEIKLE
}

Gonzalo Suárez Prado*

\section{Aristóteles es un nombre que a} todos nos suena conocido. Se sabe que este discípulo de Platón, maestro de Alejandro Magno y fundador del Liceo, es uno de los personajes más importantes del pensamiento filosófico clásico. Es, indudablemente, un punto obligado de referencia en múltiples materias. Y la economía no es una excepción. Aunque su trabajo sobre el tema abarca unas seis páginas en la edición de Bekker, principalmente ubicadas en Ética Nicomaquea, capítulo 5.5 y en Política, capítulo 1, su posición influyó en la escolástica medieval, la enseñanza social católica, en el pensamiento económico islámico, en el liberalismo y los grandes clásicos (Smith, Ricardo), en el marxismo, en la escuela jevoniana, en la economía matemática e incluso en el neoliberalismo. Sus ideas son, pues, fundamentales.

Hace casi cuatro años el doctor Carlos McCadden y yo tuvimos una serie de charlas sobre las fronteras entre la economía y la filosofía, y la conveniencia o no de la aplicación del conocimiento puro a la generación de riqueza en la práctica. Esto como parte de un proyecto que estaba desarrollando en ese momento, poco antes de asumir la Presidencia de la Asociación de Exalumnos, que ejercí durante el año de 2005. Y como parte de esas discusiones, en cierto momento brincó como referencia el texto de Scott Meikle, Aristotle’s Economic Thought. En algún

\footnotetext{
* Departamento Académico de Estudios Generales, ITAM.
} 
punto, y reconociendo el mérito del texto, nos propusimos traducir ese libro por su importancia al definir este tipo de temas. En el proceso, que nos tomó los tiempos libres de un año en primer borrador, un año en la revisión técnica y un tercer año en la corrección junto con la gestión de los derechos ante Oxford University Press y el tipografiado final a cargo de María Esther Sedano, nos surgían dudas como las siguientes: “¿es o no es el Padre de la economía? ¿Puede un hombre que vivió hace 2,330 años seguir influyendo en el mundo de hoy? ¿Pueden sus ideas estar vigentes aún?"

Para mi exposición de esta tarde, propongo la siguiente metodología: revisar algunas definiciones planteadas en el texto aristotélico, particularmente aquellas que sobre el intercambio fija en el capítulo 1 de la Politi$c a$, y que están presentes en el capítulo 3 del libro que presentamos esta noche, y luego contrastar su validez.

Comencemos definiendo la oikonomikê. La gente coopera en el uso de sus capacidades humanas comunes para hacer o cultivar cosas que podrán satisfacer sus necesidades para que haya 'suficiente'. La polis debe ser autarkês; necesita riqueza para ser autarkês; es parte de la buena vida y consiste en las herramientas o cosas útiles.

Hablemos ahora de la chrêmatistikê. Dice el texto, y cito: "porque hay otro tipo de adquisición [ktêtikê] que es especialmente llamada adquisición de riqueza [chrêmatistikê], y que se llama así con justicia; y para este tipo es correcto pensar que no debe haber límite a la riqueza y la propiedad" (p. 54). Este tipo de adquisición no es natural, pero es realizada por un cierto tipo de habilidad o arte adquirido. "La verdadera riqueza (ho alêthinos ploutos) es el inventario de cosas que son útiles en la comunidad [koinônia] de las administraciones domésticas o de la polis" (p. 56). "La riqueza como un todo consiste en usar las cosas en lugar de poseerlas; ésta es realmente la actividad de la propiedad que constituye la riqueza" (p. 56).

El intercambio [metablêtikê] "surge primero de lo que es natural, de la circunstancia de que algunos tienen demasiado poco, otros tienen mucho" (p. 59). Dentro del esquema aristotélico de pensamiento, se 
consideran tres tipos de intercambio: el trueque, en el que un bien de consumo se cambia por otro bien de consumo; el intercambio con dinero, en el que un bien de consumo se intercambia por dinero; $y$, ése, a su vez, por otro bien de consumo. El fin radica en los bienes de consumo, no en la obtención de dinero. Por último, en el intercambio por dinero se intercambia dinero por un bien de consumo, pero con la finalidad de obtener más dinero y no por el bien de consumo en sí mismo.

Como un ejemplo de este intercambio inadecuado, se cita el cuchillo délfico. El cuchillo délfico aparece como una herramienta cruda que puede servir como cuchillo, lima, y martillo, y su ventaja era que era barato. Se ofrecía en la ciudad de Delfos, y más que una herramienta útil constituía lo que hoy podríamos llamar 'un souvenir', un recuerdo de la visita a Delfos. Aristóteles crítica al avaro "herrero que diseñó el cuchillo délfico para muchos usos" cuando realmente "cada instrumento es mejor hecho cuando se hace para un uso y no para varios" (p. 63). Esta posición parece más ética que económica, porque no importa el valor percibido para el consumidor, sino que el producto sea bueno para un uso concreto, para el que está expresamente pensado.

Aunque hay mucho más que decir de estos textos, y otras definiciones, precisiones y ejemplos que no estoy incluyendo en este breve resumen, creo que tenemos suficientes elementos para hacer el siguiente ejercicio: preguntarnos si tales definiciones son vigentes y aplicables a ciertos casos de la realidad contemporánea.

No les daré las respuestas; fiel al espíritu del "abuelo intelectual" de Aristóteles, Sócrates, plantearé las preguntas y dejaré que ustedes respondan puesto que, a decir de Platón, "ya conocen la verdad, sólo deben recordarla".

Les propongo que partamos de atrás hacia delante, de lo más particular hacia lo más general. Empiezo, pues, con el caso más reciente citado, el cuchillo délfico del siglo veintiuno.

Partamos por el símil moderno del cuchillo délfico. Hoy que tenemos teléfonos con cámaras fotográficas y de video, reproductores de audio capaces de guardar varias películas o diez mil canciones, acceso a internet, localización vía satélite a través del Global Position System... surge 
una pregunta netamente aristotélica: ¿es mi teléfono un buen teléfono? ¿Sirve para su función de ser teléfono? ¿Pierde mucho al combinar muchos usos en un solo aparato? ¿Su fabricante lo hace para resolver una necesidad específica de la mejor manera posible (transmitir el sonido a la distancia) o con la intención de ganar dinero? ¿Qué tan bueno es su celular multiusos como teléfono? ¿Se escucha bien?

Otra pregunta, ahora sobre metablêtikê: hoy, ¿prevalece el trueque, el intercambio que satisface las necesidades y se apoya en el dinero para ello, o un intercambio que sólo procura la ganancia monetaria? Si le pagáramos el software a Bill Gates con pescados, ¿podría haber acumulado la tercer fortuna más grande del mundo, partiendo de apenas 500 dólares y una computadora? No lo creo. Una gran fortuna, como la que transformó a este jovencito detenido por comprar cervezas con identificaciones falsas en un gran filántropo globalmente conocido, no podría acumularse sólo en bienes perecederos acumulados por su valor de uso.

Pasemos ahora a una ciudad. ¿En verdad estamos utilizando bien los recursos con que contamos?¿La asignación es óptima? No lo creo. Por ejemplo, como país, el Distrito Federal representa siete diezmilésimas del territorio nacional, pero aporta casi el 25\% del PIB nacional. Es cierto que esto genera ciertos beneficios y crea mercados más grandes. Claro que eso implica que no es posible que seamos una polis autarkês como lo sugiere Aristóteles.

Preguntemos ahora el tipo de apropiación que predomina hoy en el mundo, ciertamente no vinculada a la apropiación por uso sino a la apropiación por intercambio. No en balde los grandes acumuladores se perciben como villanos, sea el Rico McPato de Disney o el Sr. Burns de Los Simpson. O, citando la frase célebre de la película El Padrino, "Detrás de toda gran fortuna hay siempre un gran crimen".

No estoy a favor de una distribución homogénea de la riqueza y del bienestar, pero ciertamente sí estoy a favor de una distribución homogénea de las oportunidades y de que podamos, como sociedades, garantizar un nivel mínimo de satisfactores básicos a toda nuestra población. En tanto que el $70 \%$ de la población adulta de México padece sobrepeso 
u obesidad, casi un 5\% de los mexicanos padecen trastornos alimenticios severos. A nivel mundial, hay personas muriendo de hambre y personas padeciendo por excesos. O aún más, hay quien posee lo que no utiliza en tanto alguien carece de lo más básico.

De esta comparación del mundo de hoy y de las definiciones que propone Aristóteles, podemos encontrar que siguen siendo vigentes, al menos en parte. No puedo dejar de pensar que, por hacerle caso en temas como el rechazo a la usura o a la apreciación de las inversiones, la Edad Media fue un período de bajo crecimiento económico y baja calidad de vida. Pero tampoco puedo dejar de considerar que la valoración del intercambio, cuyo fin es la acumulación de dinero, también está ofreciendo un alto costo para nuestras sociedades.

No me gusta el mundo como es hoy. Particularmente, recuerdo una idea del autor que nos reúne esta noche: quien tiene muy poco no lo goza, porque no tiene lo suficiente para satisfacer su necesidad básica; quien tiene mucho no lo goza, porque tiene miedo a perder lo que tiene y no lo utiliza. Es el equilibrio, la medianía, lo que hoy podríamos llamar "clase media" el verdadero camino a la felicidad. Parece que, de hacerle caso a Aristóteles, podría existir un mundo mejor.

Respecto a preguntas más teóricas y más técnicas, del tipo "Aristóteles, ¿hizo o no hizo economía? ¿Su pensamiento económico es una colección de comentarios o ideas sueltas, o vinculadas a otros temas éticos, políticos o metafísicos, sin una vinculación directa entre sí, o son parte de un corpus integrado, sistemático, ordenado y profundamente influyente en todo lo que de economía se ha hecho?" A este tipo de preguntas les contestaré con una solución: ¡Lean El pensamiento económico de Aristóteles en la edición del ITAM y busquen su respuesta! A todos ustedes, muchas gracias por su presencia y por acompañarnos en estas reflexiones. 
La reproducción total o parcial de este artículo se podrá hacer si el ITAM otorga la autorización previamente por escrito. 